\title{
PERBANDINGAN PENENTUAN BEST VISUS SPHERE (BVS) DENGAN MENGGUNAKAN METODE FOF UN FOG DAN DUOCHROME
}

\author{
Arief Witjaksono $^{1)}$, Nelly Riani ${ }^{1)}$ \\ awitjaks07@yahoo.co.id \\ ${ }^{1}$ Program Studi Diploma Tiga Refraksi STIKes Dharma Husada Bandung
}

\begin{abstract}
ABSTRAK
Dalam penentuan Best Visus Sphere (BVS) mempunyai beberapa metode, tetapi yang lebih sering digunakan di STIKes Dharma Husada Bandung adalah metode Refinement sphere, sedangkan menurut dua pendapat berbeda yang menyatakan penentuan Best Visus Sphere (BVS) dengan menggunkan metode duochrome dan fog unfog lebih teliti dibandingkan metode yang lainya. Tujuan penelitian ini adalah untuk mengetahui perbandingan efektifitas dan efesiensi antara metode fog unfog dan duochrome. Metode yang digunakan dalam penelitian ini adalah penelitian deskriftif. Sampel dalam penelitian ini adalah 52 orang mahasiswa DIII refraksi optisi dengan pasien sebanyak 26 orang, instrument yang digunakan adalah lembar observasi. Hasil penelitian menunjukan metode duochrome lebih efektif dibandingkan metode fog unfog selain itu metode duochrome memiliki efisiensi $100 \%$ dibandingkan metode fog unfog. Dengan demikian, diharapkan ahli Refraksi Optisi dapat menggunakan metode duochrome dalam menentukan Best Visus Sphere (BVS) agar hasilnya lebih efektif dan efisien.
\end{abstract}

Kata kunci $\quad$ : Perbandingan, Best Visus Sphere (BVS), Duochrome, Fog Un Fog.

\section{ABSTRACT \\ COMPARISON OF BEST VISUS SPHERE (BVS) DETERMINATION USING FOG UNFOG AND DUOCHROME METHOD}

Determination Best Visus Sphere (BVS) have some methods, but more often used in STIKes Dharma Husada Bandung is refinement sphere, whereas according to two different opihions stating the determination of Best Visus Sphere (BVS) using duochrome and fog unfog methods is more through than other methods. The purpose of this study is to know the comparison of effective and efficient comparison is between fog unfog and duochrome method. The method used in this research is quantitative descriptive. Sample in this research is 52 student of Diploma III of refraction optisien respondent and patients as many as 26 people, where the instrument used is the observation sheet.The results showed that the duochrome method was more effective than the fog unfog besides that duochrome method has 100\% efficiency compared to fog unfog method. Thus, it is hoped that refractionist optisien experts may use the duochrome method in determining of Best Visus Sphere (BVS) in order to make the result more effective and efficient.

Keywords $\quad$ : Comparison, Best Visus Sphere (BVS), Duochrome, Fog UnFog.

\section{PENDAHULUAN}

Gangguan penglihatan dan kebutaan di

Indonesia terus mengalami peningkatan dengan prevalensi $1.5 \%$ dan tertinggi dibandingkan dengan angka kebutaan di negara - negara regional Asia Tenggara seperti Bangladesh (1\%), India (0.7\%), dan Thailand $(0.3 \%)$. Penyebab gangguan penglihatan dan kebutaan tersebut adalah glaukoma (13.4\%), kelainan refraksi $(9.5 \%)$, 
gangguan retina (8.5\%), kelainan kornea (8.4 $\%$ ), dan penyakit mata lainnya (Depkes RI, 2009).

Gangguan miopia adalah gangguan yang ditandai dengan kesulitan untuk melihat suatu benda yang letaknya jauh. Secara fisiologi, gangguan myopia ditandai dengan keadaan mata yang mempunyai kekuatan pembiasan sinar yang berlebihan sehingga sinar sejajar yang datang dibiaskaan didepan retina. Gangguan hipermetropia adalah gangguan yang ditandai dengan kesulitan untuk melihat benda yang letaknya dekat dimana sinar sejajar yang datang dibiasan dibelakang retina (Ilyas,2012 ).

Dalam peraturan menteri kesehatan No.41 tahun 2015 disebutkan pemeriksaan refraksi subjektif dilakukan secara monokuler dan binokuler untuk menetapkan besarnya koreksi pada kelainan refraksi, jika ditemukan adanya kelainan organik maka selanjutnya dirujuk ke dokter mata. Pemeriksaan subjektif merupakan sebuah tahapan langkah demi langkah yang melibatkan kerjasama pasien untuk mengevaluasi ketajaman target penglihatan sebagai serangkaian perbandingan beberapa uji coba lensa yang diberikan oleh pemeriksa. Pemeriksaan subyektif terdiri beberapa tahapan yaitu: Penentuan visus dasar terbaik dan ketajaman penglihatan, Penentuan Best Visus Sphere (BVS), metode penentuan astigmatisme, teknik keseimbangan binokuler, titik akhir binokuler, mencatat hasil akhir dengan Best Corrected Visual
Acuity (BCVA) salah satu mata dan kedua mata (Elliott, 2008).

Best Visus Sphere (BVS) merupakan penglihatan spheris terbaik yang dirasakan pasien, hal ini dilakukan dengan menggunakan lensa yang dapat memberikan penglihatan terbaik hanya dengan kekuatan spheris dengan menggunakan lensa plus (+) atau minus (-) untuk menggambarkan suatu keadaan, dengan tahapan yang biasanya dimulai dari plus atau minus (+/-) $0.50 \mathrm{D}$ atau lebih (Kristen, 2005). Koreksi Lensa Spheris sangat penting dilakukan untuk mengetahui Best Visus Sphere (BVS). Bila menggunakan teknik Best Visus Sphere (BVS) tanpa retinoscopy, praktisi harus menemukan jumlah maksimum power positif atau jumlah minimum power negatif yang dapat ditoleransi oleh mata, tanpa menyebabkan kaburnya penglihatan diretina. Setelah occlusion, tugas pertama adalah mengukur penglihatan tanpa bantuan. Jika pasien mengatakan penglihatan lebih jelas atau identik dengan lensa plus +0.25 DS ditambahkan ke trial frame dan lakukan secara urutannya dan berulang dengan menambahkan lensa DS +0.25 lagi. Tapi jika pasien mengatakan plus tidak lebih baik, maka tambahkan minus -0.25 DS ditambahkan trial frame dan sekali lagi urutannya berulang. Dengan metode ini, akomodasi dapat diinduksi bila power minus ditambahkan ke trial frame, tapi selalu tambahkan plus, karena itu mata tanpa akomodasi, sebelum melakukan probling lens (Elliott, 2008). 
Dalam penentuan Best Visus Sphere (BVS) Meliputi; Refinement Sphere, Duochrome (Kolker, 2014), Jackson Cross Cylinder (Borish Volume 2), Fog UnFog (Essilor Academy Europe, 2008). Metode Fog UnFog dapat digunakan untuk menemukan apakah mata masih berakomodasi. Biasanya praktisi menggunakan metode refinement spherical untuk menentukan Best Visus Sphere dengan cek awal dan "fine tuning" mengikuti hasil penilaian objektif untuk refraksi ini : penentuan monokuler dengan Spheris. Padahal metode Fog UnFog adalah metode yang telah terbukti dari beberapa metode pemeriksaan subjektif . Hal ini dapat dicapai karena lensa pasien yang berada di depan mata pasien sehingga seolah-olah bayangan di depan retina, menyebabkan penglihatan kabur (Essilor Academy Europe, 2008).

$\begin{array}{rrrr}\text { Menurut } & \text { Kolker } & \text { (2014) } & \text { metode } \\ \text { refinement } & \text { spherical } & \text { hanya } & \text { dapat }\end{array}$
menentukan koreksi spheris saja namun tidak dapat menentukan titik akhir monokuler, sehingga untuk pasien yang tanpa mempunyai kelainan astigmatisme dapat langsung dilakukan pemeriksaan titik akhir monokuler dengan menggunakan metode douchrome (Kolker, 2014 ).

Berdasarkan dari dua pendapat tentang penentuan Best Visus Sphere (BVS) ada dua metode yang digunakan yaitu Fog UnFog dan Duochrome, karena itu peneliti melakukan wawancara terhadap 10 orang mahasiswa tingkat 3 prodi DIII Refraksi Optisi STIKes Dharma Husada Bandung, diketahui bahwa 1 dari 10 menggunakan douchrome dan 9 dari 10 mahasiwa menggunakan refinement sphere dan fogging karena dengan menggunakan metode refinement sphere dan fogging teknik lebih menghemat waktu dibanding dengan menggunakan metode fog unfog dan duochrome.

Tujuan penelitian untuk mengetahui efektifitas dan efesiensi pemeriksaan penentuan Best Visus Sphere (BVS) dengan menggunakan metode Fog UnFog dengan Douchrome di STIKes Dharma Husada Bandung tahun 2018.

\section{METODE PENELITIAN}

Metode penelitian berupa deskriptif kuantitatif untuk mengetahui penentuan penggunakan metode Best Visus Sphere (BVS). Pengambilan data menggunakan pendekatan Cross Sectional untuk memperlajari hubungan antara faktor-faktor risiko dengan hasil, dengan cara pendekatan, observasi atau pengumpulan data sekaligus pada satu waktu (Notoatmodjo, 2010).

Populasi penelitian adalah mahasiswa Refraksi Optisi reguler tingkat akhir angkatan 2015 sebanyak 52 orang, yaitu mahasiswa yang telah lulus Ujian Akhir Program. Sampel penelitian adalah 52 orang mahasiswa regular Refraksi Optisi STIKes Dharma Husada Bandung angkatan 2015 yang dinyatakan sudah lulus Ujian Akhir Program dan dinyatakan kompeten dalam melakukan pemeriksaan Refraki Klinik. 
Instrumen penelitian berupa lembar observasi Best Visus Sphere (BVS) untuk menilai waktu dan hasil pemeriksaan. Data primer yang diperoleh berupa lamanya waktu pemeriksaan dengan hasil ukur tidak efektif dan efektif tentang perbandingan pemeriksaan Best Visus Sphere (BVS) dengan dua metode yaitu metode Fog Un Fog dan Duochrome.

Metode pengumpulan data meliputi :

a. Meminta izin kepada 52 responden untuk melakukan perbandingan penentuan Best Visus Sphere dengan menggunakan metode Fog UnFog dan Duochrome

b. Dari 52 responden dibagi menjadi dua kelompok yaitu kelompok Fog UnFog dan Duochrome dengan jumlah 26 orang setiap kelompoknya c. Peneliti menyediakan pasien hanya mempunyai ukuran kacamata spheris tanpa astigmat sebanyak 26 orang untuk di periksa dengan dua metode berbeda

d. Setiap responden melalukan pemeriksaan satu metode dengan satu pasien yang akan atau sudah di periksa dengan metode yang lainnya.

Perbandingan penentuan Best Visus Sphere (BVS) dengan menggunakan metode Fog UnFog dan Duochrome dianalisa secara unvariat dan disajikan dalam tabel distribusi frekuensi dengan menggunkan rumus, yaitu :

$$
\mathrm{P}=\frac{F}{N} \times 100 \%
$$

$\mathrm{P}=$ Persentase

$\mathrm{F}=$ Jumlah objek yang diteliti

$\mathrm{N}=$ Jumlah seluruh Frekuensi

\section{HASIL}

Tabel 1 Hasil Penelitian Menggunakan Metode Fog UnFog

\begin{tabular}{|c|c|c|c|c|c|}
\hline No. Respoden & $\begin{array}{l}\text { Power } \\
\text { Spheris } \\
\end{array}$ & Visus & $\begin{array}{l}\text { Visus } \\
\text { Fog Unfog }\end{array}$ & Power & Waktu \\
\hline 1 & 2 & 3 & 4 & 5 & 6 \\
\hline 1 & -1.75 & $6 / 6$ & $6 / 20$ & -1.75 & 1 menit 15 detik \\
\hline 2 & -1.50 & $6 / 6$ & $6 / 20$ & -1.50 & 1 menit 53 detik \\
\hline 3 & -0.25 & $6 / 6$ & $6 / 60$ & -0.25 & 1 menit 47 detik \\
\hline 4 & +0.25 & $6 / 6$ & $6 / 60$ & +0.25 & 1 menit 3 detik \\
\hline 5 & -0.50 & $6 / 6$ & $6 / 60$ & -0.50 & 1 menit 15 detik \\
\hline 6 & -2.00 & $6 / 6$ & $6 / 60$ & -2.00 & 1 menit 35 detik \\
\hline 7 & -2.00 & $6 / 6$ & $6 / 30$ & -2.00 & 1 menit 10 detik \\
\hline 8 & -1.50 & $6 / 6$ & $6 / 60$ & -1.25 & 1 menit 5 detik \\
\hline 9 & -1.50 & $6 / 6$ & $6 / 60$ & -1.50 & 1 menit 30 detik \\
\hline 10 & -1.25 & $6 / 6$ & $6 / 60$ & -1.00 & 38 detik \\
\hline 11 & +0.50 & $6 / 6$ & $6 / 60$ & +0.75 & 1 menit 30 detik \\
\hline 12 & +0.25 & $6 / 6$ & $6 / 60$ & +0.50 & 50 detik \\
\hline 13 & +0.25 & $6 / 6$ & $6 / 30$ & +0.50 & 1 menit 40 detik \\
\hline 14 & +0.50 & $6 / 6$ & $6 / 24$ & +0.75 & 1 menit \\
\hline
\end{tabular}




\begin{tabular}{|c|c|c|c|c|c|}
\hline No. Respoden & $\begin{array}{l}\text { Power } \\
\text { Spheris } \\
\end{array}$ & Visus & $\begin{array}{l}\text { Visus } \\
\text { Fog Unfog } \\
\end{array}$ & Power & Waktu \\
\hline 15 & +0.50 & $6 / 6$ & $6 / 30$ & +0.50 & 2 menit \\
\hline 16 & +0.25 & $6 / 6$ & $6 / 30$ & +0.50 & 38 detik \\
\hline 17 & -3.25 & $6 / 6$ & $6 / 30$ & -3.00 & 57 detik \\
\hline 18 & -3.50 & $6 / 6$ & $6 / 30$ & -3.25 & 46 detik \\
\hline 19 & -1.50 & $6 / 6$ & $6 / 30$ & -1.25 & 40 detik \\
\hline 20 & +0.25 & $6 / 6$ & $6 / 39$ & +0.25 & 40 detik \\
\hline 21 & +0.25 & $6 / 6$ & $6 / 30$ & +0.25 & 46 detik \\
\hline 22 & -1.75 & $6 / 6$ & $6 / 30$ & -1.50 & 1 menit 4 detik \\
\hline 23 & -0.75 & $6 / 6$ & $6 / 30$ & -0.50 & 33 detik \\
\hline 24 & -0.25 & $6 / 6$ & $6 / 24$ & -0.25 & 1 menit 42 detik \\
\hline 25 & +0.50 & $6 / 6$ & $6 / 44$ & +0.75 & 37 detik \\
\hline 26 & +0.50 & $6 / 6$ & $6 / 45$ & +0.50 & 46 detik \\
\hline \multicolumn{5}{|c|}{ Rata-rata waktu pemeriksaan : } & 1 menit 08 detik \\
\hline
\end{tabular}

Tabel 1 menunjukan bahwa hasil pemeriksaan pasien spheris mempunyai power yang sama setelah dilakukan koreksi Best Visus Sphere (BVS) dengan menggunkan metode Fog UnFog sebanyak 13 pasien $(50 \%)$ mengalami perubahan power dan sebanyak 13 pasien (50\%) tidak mengalami perubahan power. Pada kasus pasien myopia power menjadi lebih kecil dan untuk pasien hypermetropia power menjadi lebih besar.

Tabel 2 Hasil Pemeriksaan Menggunakan Metode Duochrome

\begin{tabular}{ccccccc}
\hline No.Respoden & $\begin{array}{r}\text { Power } \\
\text { Sph } \\
\text { eris }\end{array}$ & Visus & Identifikasi & Power & Identifikasi & Waktu \\
\hline $\boldsymbol{1}$ & $\mathbf{2}$ & $\mathbf{3}$ & $\mathbf{4}$ & $\mathbf{5}$ & $\mathbf{6}$ & $\mathbf{7}$ \\
\hline 1 & -1.75 & $6 / 6$ & merah & -1.75 & Merah & 15 detik \\
\hline 2 & -1.50 & $6 / 6$ & merah & -1.50 & Merah & 05 detik \\
\hline 3 & -0.25 & $6 / 6$ & merah & -0.25 & Merah & 14. detik \\
\hline 4 & +0.25 & $6 / 6$ & Hijau & +0.50 & Merah & 23 detik \\
\hline 5 & -0.50 & $6 / 6$ & merah & -0.50 & Merah & 05 detik \\
\hline 6 & -2.00 & $6 / 6$ & merah & -2.00 & Merah & 08 detik \\
\hline 7 & -2.00 & $6 / 6$ & merah & -2.00 & Merah & 07 detik \\
\hline 8 & -1.50 & $6 / 6$ & merah & -1.50 & Merah & 06 detik \\
\hline 9 & -1.50 & $6 / 6$ & merah & -1.50 & Merah & 06 detik \\
\hline 10 & -1.25 & $6 / 6$ & merah & -1.25 & Merah & 06 detik \\
\hline 11 & +0.50 & $6 / 6$ & merah & +0.50 & Merah & 06 detik \\
\hline 12 & +0.25 & $6 / 6$ & merah & +0.25 & Merah & 11 detik \\
\hline 13 & +0.25 & $6 / 6$ & Hijau & +0.50 & Merah & 20 detik \\
\hline 14 & +0.50 & $6 / 6$ & HIjau & +0.75 & Merah & 18 detik
\end{tabular}




\begin{tabular}{cccllll}
\hline No.Respoden & $\begin{array}{r}\text { Power } \\
\text { Sph } \\
\text { eris }\end{array}$ & Visus & Identifikasi & Power & Identifikasi & Waktu \\
\hline 15 & +0.50 & $6 / 6$ & merah & +0.50 & Merah & 06 detik \\
\hline 16 & +0.25 & $6 / 6$ & merah & +0.25 & Merah & 06 detik \\
\hline 17 & -3.25 & $6 / 6$ & merah & -3.25 & Merah & 06 detik \\
\hline 18 & -3.50 & $6 / 6$ & merah & -3.50 & Merah & 07 detik \\
\hline 19 & -1.50 & $6 / 6$ & merah & -1.50 & Merah & 07 detik \\
\hline 20 & +0.25 & $6 / 6$ & merah & +0.25 & Merah & 18 detik \\
\hline 21 & +0.25 & $6 / 6$ & merah & +0.25 & Merah & 16 detik \\
\hline 22 & -1.75 & $6 / 6$ & merah & -1.75 & Merah & 07 detik \\
\hline 23 & -0.75 & $6 / 6$ & merah & -0.75 & Merah & 07 detik \\
\hline 24 & -0.25 & $6 / 6$ & merah & -0.25 & Merah & 08 detik \\
\hline 25 & +0.50 & $6 / 6$ & merah & +0.50 & Merah & 08 detik \\
\hline 26 & +0.50 & $6 / 6$ & merah & +0.50 & Merah & 10 detik \\
\hline Rata-rata waktu pemeriksaan: & & & & 09 detik \\
\hline
\end{tabular}

(Sumber : Hasil Observasi Penelitian, 2018)

Tabel 2 merupakan hasil pemeriksaan Best Visus Sphere (BVS) dari 26 responden pada pasien yang mepunyai ukuran spheris dengan power yang sama dan pasien yang sama dimana sebelumnya dilakukan pemeriksaan Best Visus Sphere (BVS) dengan metode Fog UnFog. Setelah dilakukan pemeriksaan Best Visus Sphere (BVS) dengan metode duochrome didapatkan data sebanyak 23 pasien (88.5\%) tidak mengalami perubahan power dan sebanyak 3 pasien (11\%) mengalami perubahan power yaitu hanya pada kasus pasien hipermetropia power pasien menjadi lebih besar dari sebelum dilakukan pemeriksaan Best Visus Sphere (BVS).

Pada permeriksaan Fog UnFog yang dilakukan pada 26 pasien dengan kelainan myopia dan hypermetropia dan yang melakukan pemeriksaan 26 responden. Pada Pemriksaan menggunakan Duochrome rata-rata hasil pemeriksaan lebih cepat, tetapi pasien susah membedakan objek pada latar merah dan hijau dikarenakan pencahayaan ruangan yang terlalu terang untuk melakukan pemeriksaan menggunakan proyektor.

Tabel 3 Jumlah Efektifitas Perbandingan Pemeriksaan Best Visus Sphere (BVS) Dengan Menggunkan Metode Fog UnFog dan Duochrome pada ketegori presentasi

\begin{tabular}{ccc}
\hline Metode Pemeriksaan & Frekuensi & Presentasi (\%) \\
\hline Fog UnFog & 11 & $42.3 \%$ \\
\hline Duochrome & 15 & $57.7 \%$ \\
\hline Jumlah & 26 & $100 \%$ \\
\hline
\end{tabular}


Tabel 3 menunjukan metode Fog UnFog dari hasil 11 pemeriksaan (42.3\%) efektif dan metode duochrome menunjukan bahwa 15 pemeriksaan $(57.7 \%)$ efektif.

Tabel 4 Jumlah Efisiensi Perbandi ngan Pemeriksaan Best Visus Sphere (BVS) Dengan Menggunkan Metode Fog UnFog dan Duochrome pada ketegori Presentasi

\begin{tabular}{ccc}
\hline Metode Pemeriksaan & Frekuensi & Presentasi (\%) \\
\hline Fog UnFog & 0 & $0 \%$ \\
\hline Duochrome & 26 & $100 \%$ \\
\hline Jumlah & 26 & $100 \%$ \\
\hline
\end{tabular}

Berdasarkan tabel 4 diatas menunjukan bahwa metode Fog UnFog dari hasil 0 pemeriksaan (0\%) efisien dan metode duochrome menunjukan bahwa 26 pemeriksaan (100\%) efisien.

\section{PEMBAHASAN}

Berdasarkan tabel 1 dan 2 didapatkan hasil pemeriksaan pada kasus pasien nomor urut pertama pada pemeriksaan Best Visus Sphere (BVS) dengan menggunakan metode Fog UnFog dan Duochrome mempunyai nilai efektifitas yang ditentukan dengan power hasil pemeriksaan Best Visus Sphere (BVS) memiliki kekuatan power yang sama tetapi jika dilihat dari segi efisiensi pemeriksaan yang diukur dengan kecepatan waktu, metode Duochrome memiliki tingkat efisiensi yang lebih baik karena metode Fog UnFog menggunakan lensa fogging yang terlalu besar $(+1.50)$ dan duochrome hanya menggunakan lensa kerja +0.25 .

Berdasarkan table .1 dan .2 didapatkan hasil pemeriksaan pada kasus pemeriksaan pasien dengan nomor urut delapan pemeriksaan Best Visus Sphere (BVS) dengan menggunakan metode Fog UnFog dan Duochrome mempunyai nilai efektifitas yang berbeda. Metode Fog UnFog menunjukan nilai efektifitas yang lebih baik jika bandingkan dari metode Duochrome karena hasil power pada pemeriksaan sesuai dengan teori Elliot (2008) yang menyatakan bahwa pada pasien myopia yang diambil hasil pemeriksaan adalah power yang terkecil sedangkan pada pasien hypermetropia yang diambil hasil pemeriksaan adalah power terbesar. Metode Fog UnFog dengan penambahan lensa fogging +1.50 melemahkan akomodasi pada mata pasien sehingga power pemeriksaan yang dihasilkan dengan metode Fog UnFog lebih teliti sedangkan metode Duochrome dengan penambahan lensa +0.25 masih memungkinkan untuk mata pasien mengalami akomodasi.

Untuk nilai efisiensi pada kasus pemeriksaan nomor urut delapan metode duochrome mempunyai nilai efisiensi yang lebih baik. Tetapi nilai efektifitas lebih utama dibandingkan dengan nilai efisiensi. Berdasarkan teori menurut siagian (2001) Jika hasil suatu pekerjaan semakin mendekati 
sasaran, berarti makin tinggi efektifitasnya denga metode Duochrome didadaptakan waktu lebih baik tetapi untuk penentuan pemeriksaan Best Visus Sphere (BVS) yang diutamakan adalah ketepatan power. Jadi untuk kasus pasien pemeriksaan nomor urut delapan nilai yang diambil adalah hasil pemeriksaan dengan menggunakan metode Fog UnFog.

Berdasarkan hasil penelitian penentuan Best Visus Sphere (BVS) dengan metode Fog UnFog dan Duochrome mempunyai hasil yang sama berdasarkan dua metode didapatkan hasil dari 15 pemeriksaan (57.7\%) maka penilaiannya berdasarkan perbandingan efisiensi dari segi waktu pemeriksaan. Hasil penelitian penentuan Best Visus Sphere (BVS) dengan metode Fog UnFog dan Duochrome menunjukan

\section{Kesimpulan}

1. Metode duochrome (57.7\%) lebih efektif dibandingkan dengan metode fog unfog $(42.3 \%)$.

2. Metode duochrome (100\%) lebih efisien dibandingkan dengan metode fog unfog $(0 \%)$.

\section{DAFTAR PUSTAKA}

American Academy of Ophthalmology, Prevalence and Cmmon Cause Of Vision Impairment In Adults, In International Ophtalmology Section 13,2005-2006,page 189-199

Arikunto S. 2010. Metodologi Penelitian Kesehatan. Jakarta : Rineka Cipta perbedaan sebanyak 11 pemeriksaan (42.3\%) maka penilaiannya berdasarkan perbandingan efektifitasnya yaitu ketepatan hasil pemeriksaan.

Dalam penelitian ini didapatkan metode yang efektif dan efisien adalah metode duochrome, hal ini dapat dikatakan sejalan dengan penelitian yang dilakukan Dewi (2016) yang menyatakan bahwa metode duochrome lebih sering digunakan oleh Refraksi Optisi dibandingkan dengan metode lain. Menurut Ilyas (2012), pada pemeriksaan menggunakan metode duochrome Mata myopia akan melihat warna merah lebih jelas sedangkan mata hipermetropia akan melihat warna hijau yang lebih jelas. Tujuannya adalah untuk mengetahui bahwa pasien sudah mendapatkan penglihatan atau koreksi kaca mata yang sesuai dari mata yang diperiksa.

Depkes RI. 2009 .Gangguan Penglihatan Masih Menjadi Masalah Kesehatan. http://www.depkes.go.id/index.php/berita/ press-relase/845-gangguan-penglihatanmasih-menjadi-masalah-kesehatn.html diakses tanggal 10 januari 2018

Elliott, DB.Clinical Procedure Sin Primary Eye care3/e.Oxford,Elsevier,2008.

Essilor academy europea.2008. page 22-23

Hasibuan M S P. 1984 .Manajemen Dasar, Pengertian dan Masalah. Jakarta : Gunung Agung

Hidayat A A.. 2007. Riset Keperawatan dan Teknik Penulisan Ilmiah. Jakarta: Salemba 
Ibeinmo Opubiri \& chinyere pedro-Egbe. The Pan African Medical Journal. 2013

Ilyas S. 2012 . Dasar Teknik Pemeriksaan Dalam Ilmu Penyakit Mata.edisi ke 4. Jakarta: Fakultas Kedokteran Universitas Indonesia

$$
\text { . 2013. Ilmu Penyakit Mata }
$$

Edisi Keempat. Jakarta:fakultas kedokteran universitas Indonesia

Kolker R J. 2014.Subjective Refraction and Prescribing Glasses. Page 28-36

Maksus A I. 2016 . Standar Prosedur Pemeriksaan Refraksi. Jakarta: Fakultas Kedokteran Universitas Indonesia

Notoatmodjo S. 2012. Metode Penelitian Kesehatan.Jakarta: Rineka Cipta
Peraturan Menteri Kesehatan Republik Indonesia No.41 th 2015 Tentang Standar Pelayanan Refraksi Optosien/Optometri Mentri Kesehatan Republik Indonesia.http://www.iropin.org/legalitas/ PMK\%20\%No.\%2041\%20ttg\%20Standar \%20Pelayanan\%20Refraksi\%20Optisi\%2 0Optometri.pdf. Diakses tgl 5 januari 2018

Ratna N K, 2010. Metode Penelitian : Kajian Budaya dan Ilmu Social Humaniara Pada Umumnya. Yogjakarta: Pustaka Pelajar

Siagian S P. 2001 .Manajemen Sumber Daya manusia. Jakarta : Bumi Aksara

Sugiyono. 2013 . Metode Penelitian Pendekatan Kuantitatif, kualitatif dan $R \& D$. Bandung: Penerbit CV. Alfabeta 